\title{
Physical Solubility of Total Reduced Sulfurs in Fe-Chelate Aqueous Solutions
}

\author{
Maria C. Iliuta* and Faïçal Larachi
}

Department of Chemical Engineering, Laval University, Québec, G1K 7P4, Canada

\begin{abstract}
Total reduced sulfurs (TRS) include hydrogen sulfide $\left(\mathrm{H}_{2} \mathrm{~S}\right)$, methyl mercaptan (methanethiol, $\mathrm{CH}_{3} \mathrm{SH}$ ), dimethyl sulfide $\left(\mathrm{CH}_{3} \mathrm{SCH}_{3}\right)$ and dimethyl disulfide $\left(\mathrm{CH}_{3} \mathrm{~S}_{2} \mathrm{CH}_{3}\right)$ and are referred to as noncondensible gases. They are part of a well-known environmental problem afflicting pulp mills exploiting the Kraft pulp mill process. These sulfur compounds are formed in the Kraft pulping process and come in contact with different waters and liquors, contributing to the odor problems of Kraft mills. Because of their toxic and corrosive characters, they must be removed down to very low concentration levels. The olfactory threshold of TRS for human beings is four orders of magnitudes below the regulated emission level which is approximately 5-10 ppm in Canada and the US, giving rise to strict regulations in order to reduce their emissions from specific sulfate pulp process equipments. Among several approaches proposed to remove or at least reduce these airborne pollutants, the utilization of ferric chelate complex of trans-1,2-cyclohexane diaminetetraacetic acid (CDTA) for the oxidative scrubbing of hydrogen sulfide and methyl mercaptan in Kraft mill streams is beneficial from the standpoints of iron protection against precipitation and oxygen-mediated regenerative oxidation of the ferrous chelate CDTA. The remaining (unreactive) two sulfur-bearing compounds, dimethyl sulfide and dimethyl disulfide undergo only physical absorption in such solutions. The physical solubility of these four compounds in aqueous CDTA-Fe(III) alkaline solutions is therefore a crucial parameter for designing the complete scrubbing-absorption process. The aim of this review is to highlight several aspects related to the solubility of TRS compounds in Fe-chelate aqueous solutions (experimental methods, solubility dependence on temperature, chelate concentration, and solution $\mathrm{pH}$ ).
\end{abstract}

\section{INTRODUCTION}

The quartet of total reduced sulfurs (TRS) includes hydrogen sulfide $\left(\mathrm{H}_{2} \mathrm{~S}\right)$, methyl mercaptan (methanethiol, $\left.\mathrm{CH}_{3} \mathrm{SH}\right)$, dimethyl sulfide $\left(\mathrm{CH}_{3} \mathrm{SCH}_{3}\right)$ and dimethyl disulfide $\left(\mathrm{CH}_{3} \mathrm{~S}_{2} \mathrm{CH}_{3}\right)$. These volatile compounds are notoriously known for causing malodorous air pollution. Knowledge of their solubility is of high interest in various applications in chemical industry, oil and gas industry and in environmental protection as well. An important body of experimental work was reported in the open literature for the solubility of these sulfur compounds in various liquids [1], especially due to their toxic and corrosive characters for industrial and environmental processes and the increasing interest of removal of these sulfur compounds from gaseous streams. The systems containing hydrogen sulfide were much more extensively investigated and the available data are therefore quite abundant, especially because it is the most common sulfurcontaining compound encountered in various petroleum and non-petroleum applications. The systems containing dimethyl sulfide and dimethyl disulfide are mainly investigated in direct connection to the environmental natural processes. Even though the methyl mercaptan can also be present in various gaseous streams along with the hydrogen sulfide, investigations concerning systems containing this sulfur component are very limited.

Total reduced sulfurs are the major components known to occur in the Kraft pulp mill atmospheric emissions, and responsible for their distinctive odor problems at very low concentrations in the neighboring agglomerations. The

*Address correspondence to this author at the Department of Chemical Engineering, Laval University, Québec, G1K 7P4, Canada; Tel: 418-6562204; Fax: 418-656-5993, E-mail: maria-cornelia.iliuta@gch.ulaval.ca strong and persistent odor is due to the use of the white liquor (alkaline solutions containing sodium sulfide and sodium hydroxide) for the digestion of wood and the conversion into pulp. During operation, sodium sulfide combines with organic compounds to form organosulfur compounds (mostly organic sulfides and mercaptans).

Because of their toxic and corrosive characters, they must be removed down to very low concentration levels. Several techniques for the removal of these sulfur compounds are available and described in the literature, see for example Busca and Pistarino (2003) [2] and Normandin, Belley, Aucoin and Gagnon (2005) [3]. Among several approaches proposed to abate or at least reduce these airborne pollutants, the utilization of ferric chelate complex of trans-1,2cyclohexanediaminetetraacetic acid (CDTA) for the oxidative scrubbing of hydrogen sulfide and methyl mercaptan in Kraft mill streams is beneficial from the standpoints of iron protection against precipitation and oxygen-mediated regenerative oxidation of the ferrous chelate CDTA. The remaining two sulfur-bearing compounds, dimethyl sulfide and dimethyl disulfide, considered not oxidizable by CDTAFe(III), undergo only physical absorption in such solutions. The physical and chemical solubility of these four compounds in aqueous CDTA-Fe(III) alkaline solutions is therefore an essential parameter for designing the complete scrubbing-absorption process in many technical applications. When the sulfur compound reacts within the aqueous solutions, as in the case of $\mathrm{H}_{2} \mathrm{~S}$ and $\mathrm{CH}_{3} \mathrm{SH}$ with $\mathrm{Fe}$ (III) chelates, the genuine physical solubility cannot be measured directly. Because this interfering oxidation is absent when $\mathrm{H}_{2} \mathrm{~S}$ or $\mathrm{CH}_{3} \mathrm{SH}$ is contacted with $\mathrm{Fe}$ (II) chelates, the physical solubility of these compounds can therefore be measured in aqueous solutions in $\mathrm{Fe}$ (II) complexes of CDTA. 
The aim of this review is to highlight several aspects related to the solubility of TRS compounds in Fe-chelate aqueous solutions (experimental methods, solubility dependence on temperature, chelate concentration, and solution $\mathrm{pH})$.

\section{PHYSICAL AND CHEMICAL PROPERTIES OF TO- TAL REDUCED SULFURS}

Hydrogen sulfide $\left(\mathrm{H}_{2} \mathrm{~S}\right)$ and methyl mercaptan (MM) are gases at ambient temperature, while dimethyl sulfide (DMS) and dimethyl disulfide (DMDS) are low boiling-point volatile liquids (Table 1). Only hydrogen sulfide and methyl mercaptan can dissociate in aqueous solution [4]:

$$
\begin{aligned}
& \mathrm{H}_{2} \mathrm{~S} \stackrel{K_{1}}{\rightleftharpoons} \mathrm{HS}^{-}+\mathrm{H}^{+} \stackrel{K_{2}}{\rightleftharpoons} \mathrm{S}^{2-}+2 \mathrm{H}^{+} \\
& \mathrm{CH}_{3} \mathrm{SH} \stackrel{K}{\rightleftharpoons} \mathrm{CH}_{3} \mathrm{~S}^{-}+\mathrm{H}^{+}
\end{aligned}
$$

TRS components are highly corrosive and toxic gases [4,5]. As an example, hydrogen sulfide irritates eyes and respiratory tract at a concentration of only $20 \mu \mathrm{L} / \mathrm{L}$; at 500 $\mu \mathrm{L} / \mathrm{L}, 30 \mathrm{~min}$ of exposure causes severe sickness whereas $1000 \mu \mathrm{L} / \mathrm{L}$ and $30 \mathrm{~min}$ of exposure cause death [6]. Methyl mercaptan and dimethyl disulfide appear to be somewhat less toxic than hydrogen sulfide, but can produce similar effects only at slightly higher concentrations. Dimethyl sulfide is considerably less toxic. At low concentration, hydrogen sulfide is responsible for an odor of rotten eggs, while at high lethal concentrations, it is odorless. Hydrogen sulfide has a very wide explosion limit of (4.3 to 45.5$) \%$ (volume fraction) in air, compared to the other three sulfur compounds.

\section{TRS IN THE KRAFT PUPL MILLS EMISSIONS-AN IMPORTANT ENVIRONMENTAL PROBLEM}

Total reduced sulfurs referred to as noncondensible gases (NCG) are part of a well-known environmental problem afflicting pulp mills exploiting the Kraft pulp mill process. They are emitted from digesters, turpentine recovery systems, evaporators, brownstock washer hoods and seal tanks, knotter hoods, mud filters, causticizers, liquor and brownstock storage tanks [6]. They are formed in the Kraft pulping process and because they come in contact with different waters and liquors, they contribute to the odor problems of Kraft mills. Their composition varies widely from system to system. Two important categories are encountered, (i) the high concentration and low volume gases (HCLV), where the TRS gases make up about $10 \%$ (volume) and (ii) the low concentration and high volume gases (LCHV), where the TRS amounts are usually less than $0.1 \%$. Among the TRS, $\mathrm{H}_{2} \mathrm{~S}$ is the most abundant in the effluents.

TRS are highly corrosive to carbon steel, especially the HCLV gases [6]. Moreover, they are highly toxic, being responsible for deaths and injuries in the pulp and paper industry. Since the early 1990's, several Canadian provincial governments and the United States promulgated a number of regulations upon the Kraft pulp manufacturers to collect and treat their total reduced sulfurs emitting vents. The olfactory threshold of TRS for human beings is four orders of magnitudes below the regulated emission level which is approximately 5-10 ppm in Canada and the US. This has ultimately given rise to strict regulations in order to reduce their emissions from specific sulfate pulp process equipments such as kilns, evaporators, washers, etc. Considering the progressive nature of legislations, it is anticipated that increasingly tighter regulations will be applicable in the near future especially in North America where about $15 \%$ of the world Kraft mills are in operation.

Various approaches have been advocated over the years to reduce the concentration of these pollutants in the effluents below environmentally acceptable limits, like the alkaline/amine scrubbing and gas incineration [5,7], chemical oxidation by $\mathrm{NaClO}, \mathrm{ClO}_{2}, \mathrm{H}_{2} \mathrm{O}_{2}, \mathrm{KMnO}_{4}$ and gas phase oxidation by $\mathrm{ClO}_{2}$ [8], aminal scavenging [9,10], wet oxidation and biofiltration [11], $\mathrm{H}_{2} \mathrm{~S}$ oxidation in aqueous ferric sulfate or chloride solutions in acidic conditions [12,13] or in slightly alkaline ferric chelate solutions [14]. An approach currently investigated in Laval University (Canada) concerns the concept of alkaline oxidative scrubbing of TRS conveyed in Kraft pulp mills NCG in order to eliminate odor and to convert TRS into valuable sulfur. Hydrogen sulfide is absorbed in ferric chelate solutions (mainly CDTA, i.e., trans1,2-diaminocyclohexanetetraacetic acid) in alkaline conditions and oxidized to elemental sulfur which can be separated periodically before the absorbing solution is recycled. Like hydrogen sulfide, methyl mercaptan is absorbed in ferric chelate solutions but is oxidized into dimethyl disulfide (DMDS) and ads up to the native fraction of dimethyl sulfide (DMS) and DMDS coming from the air effluent undergoing physical absorption in the aqueous iron chelate solutions. Due to the propensity of the bare ferric and ferrous ions to precipitate as hydroxides within neutral to alkaline media, the use of organic chelate agents, which have the capacity to bond with cationic ions, proved to be efficient to prevent

\begin{tabular}{|c|c|c|c|c|c|}
\hline Compound & Boiling point, ${ }^{\circ} \mathrm{C}$ & $\begin{array}{l}\text { Explosive concentration } \\
\text { range in air, \% [4] }\end{array}$ & $\begin{array}{l}\text { Dissociation constant in } \\
\text { aqueous solution }\left(100^{\circ} \mathrm{C}\right)[4]\end{array}$ & $\begin{array}{l}\text { Heat of combustion, } \\
\text { kcalmole }^{-1}[4]\end{array}$ & $\begin{array}{c}\text { Odor threshold, } \\
\text { ppb [5] }\end{array}$ \\
\hline $\mathrm{H}_{2} \mathrm{~S}$ & -61.8 & $4.3-45.5$ & $\begin{array}{l}\mathrm{K}_{1}=2.1 \times 10^{-7} \\
\mathrm{~K}_{2}=<10^{-14}\end{array}$ & 124 & $0.5-5$ \\
\hline MM & 5.8 & $2.2-9.2$ & $\mathrm{~K}=4.3 \times 10^{-11}$ & 229 & $0.3-3$ \\
\hline DMDS & 118 & n.a.* & n.d. & $\sim 530$ (est.) & $1-20$ \\
\hline
\end{tabular}

Table 1. Properties of the TRS Compounds

* not available; ** not dissociated. 
iron precipitation over a wide $\mathrm{pH}$ range, typically up to 10 . Another advantage of ferric chelate oxidation rests on the possibility to regenerate the ferrous chelate product into the active ferric chelate in the presence of dissolved oxygen [15]. The physical solubility of TRS in chelate-containing solutions is therefore an important parameter needed for the design of absorption scrubbing equipments in many technical applications.

\section{EXPERIMENTAL METHODS}

The solubility of $\mathrm{H}_{2} \mathrm{~S}$, a gaseous compound at ambient temperature, was measured using a gas-liquid equilibrium cell based on the saturation method [16]. Due to the very corrosive character of the methyl mercaptan for the solubility apparatus, the static headspace method (SHM) - well known as a very effective tool for analyzing volatile organic compounds present in contaminated condensed samples and wide-ranging use in environmental analysis - was chosen for studying the solubility of the other gaseous compound, MM [17]. The same SHM was used for measuring the solubility of the volatile liquids compounds, DMS and DMDS [18,19].

\section{Solubility Apparatus Based on the Saturation Method}

The main parts of the solubility apparatus consists of an equilibrium cell (EC), a gas burette (GB), a condenser (C) and two precision pressure gauges (PG1 and PG2) [16]. The equilibrium cell ensures, by means of good agitation, an appropriate gas-liquid contacting. It is connected to the condenser $\mathrm{C}$ made of stainless steel, optimized in order to practically avoid solvent loss during the degassing procedure. Because the accuracy of the solubility measurements depends strongly on the accurate measurements of the total pressure inside the equilibrium cell, the gas pressure in the equilibrium cell was measured by using a temperaturecontrolled MKS Baratron Type 628B Absolute Pressure Transducer ( 0.05 to 1000 Torr FS, precision $0.25 \%$ full scale, measurement resolution $0.001 \%$ full scale) which provides high accuracy and operation which is extremely temperature stable at operating pressure. Both the undissolved gas and the solvent vapor pressures in the gaseous mixture are determined. The temperature-controlled MKS Baratron 628B transducer used avoids vapor condensation during the measurements and allows very precise determinations of the total pressure. The pressure of the dry gas inside the thermostated gas burette GB (kept at a constant temperature using a thermostatic bath with a precision of $\pm 0.01^{\circ} \mathrm{C}$ ) was measured using a NOSHOK 100-30/15-2127 transducer (precision $0.25 \%$ full scale) at constant temperature. The equilibrium cell together with the condenser and the connecting lines up to the Baratron transducer was kept to a constant temperature using a thermostated bath controlled to $\pm 0.01^{\circ} \mathrm{C}$. A weighted quantity of solution was injected into the equilibrium cell and slowly degassed by stirring the liquid under vacuum until the base pressure of the vacuum pump was reached. After the solution degassing was completed, the vacuum pump was shut off, the equilibrium chamber was sealed and the temperature in the water thermostated bath was raised to a certain value at which the solubility measurement is to be performed. The system kept at a constant temperature $T$ reached the vapor-liquid equilibrium and the vapor pressure of the degassed solution was measured $\left(P_{V S}\right)$. The gas was added in the thermostated gas burette (kept at a constant temperature $T_{G}$ ), previously evacuated, and the pressure $P_{G 1}$ was read. The number of moles of gas in the burette was then calculated:

$n_{G 1}=\frac{P_{G 1} V_{G B}}{Z_{G 1} R T_{G}}$

After introducing a certain amount of gas into the equilibrium cell, a new pressure $P_{G 2}$ in the burette was read and the number of moles of gas remaining in the gas burette was calculated:

$n_{G 2}=\frac{P_{G 2} V_{G B}}{Z_{G 2} R T_{G}}$

The difference between $n_{G 1}$ and $n_{G 2}$ represents the number of moles of gas added in the equilibrium cell, $n_{G, \text { in }}$. The constant pressure read at equilibrium represents the total pressure (gas + vapor). It was assumed that the vapor was exclusively contributed by water. The gas partial pressure was determined by subtracting the vapor pressure of the degassed solvent from the total pressure. The number of moles of gas absorbed in the equilibrium cell $n_{G, a b s}$ was determined using relations similar to $(1,2)$ :

$n_{G, f i n}=\left(\frac{P_{t o t}}{Z_{\text {mix }}}-\frac{P_{V S}}{Z_{\text {water }}}\right) \frac{V_{G, E C}}{R T}$

$n_{G, a b s}=n_{G, i n}-n_{G, f i n}$

The volume of the gas phase in the equilibrium chamber $V_{G, E C}$ is given by the difference between the total volume $V_{E C}$ and the volume occupied by the liquid. Henry's law constant for the gas absorption in a given solution $\left(K_{H}(T)\right)$ was then calculated. The compressibility factors for pure water $\left(Z_{\text {water }}\right)$ and hydrogen sulfide $\left(Z_{G}\right)$ and their corresponding mixtures $\left(Z_{\text {mix }}\right)$ were determined using the SRK equation of state. The reproducibility of the solubility measurements was within $1 \%$.

\section{Static Headspace Method}

The headspace method is an appropriate method to analyze the volatile organic compounds (VOC) contained (absorbed) in a condensed sample. The headspace sample is prepared in a sealed vial by introducing a known volume of sample of initial concentration $C_{S}$ [17-19]. Consider this system at equilibrium consisting of the liquid phase (L) with concentration $C_{L}$ and the headspace gas phase $(\mathrm{GH})$ with concentration $C_{G H}$. A mole balance between the total moles of VOC in the sample, the moles of VOC in the liquid phase, and those in the headspace gas phase, gives:

$C_{S} V_{L}=C_{L} V_{L}+C_{G H} V_{G H}$

where $V_{L}$ and $V_{G H}$ represent the volume of the liquid phase and the gas phase in the headspace, respectively.

After rearrangement, equation (5) yields: 


$$
\frac{1}{C_{G H}}=\frac{K}{C_{S}}+\frac{1}{C_{S}} \frac{V_{G H}}{V_{L}}
$$

where

$$
K=\frac{C_{L}}{C_{G H}}
$$

represents the partition coefficient.

Taking into account that the VOC concentration in the headspace gas phase is directly proportional to the peak area of the GC response, $A_{G H}$ :

$C_{G H}=a \cdot A_{G H}$

equation (6) becomes:

$\frac{1}{A_{G H}}=\frac{a}{C_{S}} K+\frac{a}{C_{S}} \frac{V_{G H}}{V_{L}}$

According to equation (9), the partition coefficient $K$ can be obtained through plotting $1 / A_{G H}$ as a function of the ratio $V_{G H} / V_{L}$. Henry's law constant expressed in $\mathrm{Pa} \cdot \mathrm{m}^{3} \cdot \mathrm{mol}^{-1}$, deriving from the partition coefficient, is then given by:

$K_{H}(T)=\frac{R T}{K}$

\section{SOLUBILITY DATA}

Table 2 presents all experimental data published in the open literature concerning the solubility of hydrogen sulfide, methyl mercaptan, dimethyl sulfide and dimethyl disulfide in Fe-Chelate aqueous solutions. Temperature and total pressure -gas partial pressure, whenever specified- ranges as well as the estimated errors given by the authors are included. The solubility of the four components in aqueous solutions of $\mathrm{Fe}(\mathrm{II})-\mathrm{CDTA}$ or $\mathrm{Fe}$ (III)-CDTA complexes was measured at temperatures varying from 288 to $333 \mathrm{~K}$ and pressures up to 1 atm. The solution concentrations varied from 38 to 300 $\mathrm{mol} \cdot \mathrm{m}^{-3}$, expressed on CDTA basis and the $\mathrm{pH}$ varied generally between 2.2 and 8.5. CDTA concentration range and solution $\mathrm{pH}$ were limited by the usual operation conditions on the one hand, and by the solution stability on the other hand. First, typical operation conditions of iron chelate based procedures require a $\mathrm{pH}$ of the solution between 6 and 9 [14]. Because of the decrease of the $\mathrm{Fe}(\mathrm{III})$ chelate stability at alkaline $\mathrm{pH}$ (conversion to $\mathrm{Fe}(\mathrm{OH})_{3}$ ), solubility measurements were performed up to a solution of $\mathrm{pH} 8$ in order to illustrate the $\mathrm{pH}$ influence on the DMDS solubility in these solutions. Second, a numerical mass transfer study of a packed-bed scrubbing process involving EDTA-Fe(III) chelates [20] showed that a chelate feed concentration less than $100 \mathrm{~mol} \cdot \mathrm{m}^{-3}$ would be sufficient for scrubbing TRScontaining streams at the concentration levels typically encountered in industry. Therefore, the CDTA concentration used in all studies did not exceed $300 \mathrm{~mol} \cdot \mathrm{m}^{-3}$. A concentra-

\begin{tabular}{|c|c|c|c|c|}
\hline & Liquid & $T / \mathbf{K}$ & $P / \mathrm{kPa}$ & Estimated uncertainty \\
\hline \multirow{6}{*}{$\begin{array}{l}\mathrm{H}_{2} \mathrm{~S} \\
{[16]}\end{array}$} & aq. $(38,95,280)$ & 293.15 & $P_{H_{2} S}=32.86-76.01$ & $\delta T= \pm 0.01 \mathrm{~K}$ \\
\hline & & 313.15 & $P_{\mathrm{H}_{2} \mathrm{~S}}=38.82-79.99$ & $\delta x_{H_{2} S}= \pm 1 \%$ \\
\hline & & 323.15 & $P_{\mathrm{H}_{2} \mathrm{~S}}=39.95-84.13$ & \\
\hline & $\mathrm{mol} \cdot \mathrm{m}^{-3} \mathrm{CDTA}-\mathrm{Fe}(\mathrm{II})$ & 303.15 & $P_{\mathrm{H}_{2} \mathrm{~S}}=35.1-81.8$ & $\delta P / P= \pm 0.0025$ \\
\hline & & 313.15 & $P_{\mathrm{H}_{2} \mathrm{~S}}=35.2-82.8$ & $\delta x_{\mathrm{H}_{2} \mathrm{~S}}= \pm 1 \%$ \\
\hline & & 323.15 & $P_{H_{2} S}=38.6-90.5$ & \\
\hline \multirow{2}{*}{$\begin{array}{l}\text { MM } \\
{[17]}\end{array}$} & aq. $(38,60,124,300) \mathrm{mol} \cdot \mathrm{m}^{-3}$ & $298.15,303.15,308.15,313.15$, & 101 & $\delta T= \pm 0.01 \mathrm{~K}$ \\
\hline & CDTA & $318.15,323.15,328.15,333.15$ & & $\delta K_{H}= \pm 2 \%$ \\
\hline \multirow{4}{*}{$\begin{array}{c}\text { DMS } \\
{[18]}\end{array}$} & aq. $(38,60,100)$ & $288.15,293.15,298.15,303.15$, & 101 & $\delta T= \pm 0.01 \mathrm{~K}$ \\
\hline & $\mathrm{mol} \cdot \mathrm{m}^{-3} \mathrm{CDTA}$ & 308.15 & & $\delta K_{H}= \pm 2 \%$ \\
\hline & aq. $(38,60,100)$ & $288.15,293.15,298.15,303.15$, & 101 & $\delta T= \pm 0.01 \mathrm{~K}$ \\
\hline & $\mathrm{mol} \cdot \mathrm{m}^{-3} \mathrm{CDTA}-\mathrm{Fe}(\mathrm{II})$ & 308.15 & & $\delta K_{H}= \pm 2 \%$ \\
\hline \multirow{4}{*}{$\begin{array}{c}\text { DMDS } \\
\text { [19] }\end{array}$} & aq. $(38,124,300) \mathrm{mol} \cdot \mathrm{m}^{-3}$ & $298.15,303.15,308.15,313.15$, & 101 & $\delta T= \pm 0.01 \mathrm{~K}$ \\
\hline & CDTA & $318.15,323.15,328.15,333.15$ & & $\delta K_{H}= \pm 2 \%$ \\
\hline & aq. $(38,124,300) \mathrm{mol} \cdot \mathrm{m}^{-3}$ & $298.15,303.15,308.15,313.15$, & 101 & $\delta T= \pm 0.01 \mathrm{~K}$ \\
\hline & CDTA-Fe(III) & $318.15,323.15,328.15,333.15$ & & $\delta K_{H}= \pm 2 \%$ \\
\hline
\end{tabular}

Table 2. SRT Solubility Data

* data for $300 \mathrm{~mol} \cdot \mathrm{m}^{-3} \mathrm{CDTA}$ are available only at $298.15 \mathrm{~K}$. 
tion larger than $100 \mathrm{~mol} \cdot \mathrm{m}^{-3}$ was included, when possible, to illustrate the influence of CDTA concentration on the gas solubility.

First, typical operation conditions of iron chelate based procedures require a $\mathrm{pH}$ of the solution between 6 and 9 [14]. Because of the decrease of the Fe(III) chelate stability at alkaline $\mathrm{pH}$ (conversion to $\mathrm{Fe}(\mathrm{OH})_{3}$ ), solubility measurements were performed up to a solution of $\mathrm{pH} 8$ in order to illustrate the $\mathrm{pH}$ influence on the DMDS solubility in these solutions. Second, a numerical mass transfer study of a packed-bed scrubbing process involving EDTA-Fe(III) chelates [20] showed that a chelate feed concentration less than $100 \mathrm{~mol} \cdot \mathrm{m}^{-3}$ would be sufficient for scrubbing TRScontaining streams at the concentration levels typically encountered in industry. Therefore, the CDTA concentration used in all studies did not exceed $300 \mathrm{~mol} \cdot \mathrm{m}^{-3}$. A concentration larger than $100 \mathrm{~mol} \cdot \mathrm{m}^{-3}$ was included, when possible, to illustrate the influence of CDTA concentration on the gas solubility. As the presence of the sulfur component destabilizes the iron chelate complex in some conditions, the maximum concentration values depended on the solution stability. In the case of MM, this behavior was observed at a CDTA$\mathrm{Fe}(\mathrm{II})$ concentration of $300 \mathrm{~mol} \cdot \mathrm{m}^{-3}$, especially at temperatures larger than $298 \mathrm{~K}$; experimental data are therefore available up to a chelate concentration of $124 \mathrm{~mol} \cdot \mathrm{m}^{-3}$ (between 298 and $333 \mathrm{~K}$ ) and a chelate concentration of 300 $\mathrm{mol} \cdot \mathrm{m}^{-3}$ only at $298 \mathrm{~K}$ [17]. In the case of DMS, this process was observed at CDTA-Fe(II) concentrations larger than 124 $\mathrm{mol} \cdot \mathrm{m}^{-3}$ [18]. At a concentration of $124 \mathrm{~mol} \cdot \mathrm{m}^{-3}$, it is quite slow at 288 and $298 \mathrm{~K}$, and becomes faster at larger temperatures; at $300 \mathrm{~mol} \cdot \mathrm{m}^{-3}$ it is so fast that it precluded the preparation of any stable chelate solutions at room temperature. Experimental data are therefore available up to a chelate concentration of $100 \mathrm{~mol} \cdot \mathrm{m}^{-3}$ because of very good data reproducibility and actual practical interest for low CDTA$\mathrm{Fe}(\mathrm{II})$ concentration solutions.

At a constant temperature, the solubility of all sulfur components decreases with the increase of CDTA concentration (Figs. 1-5).

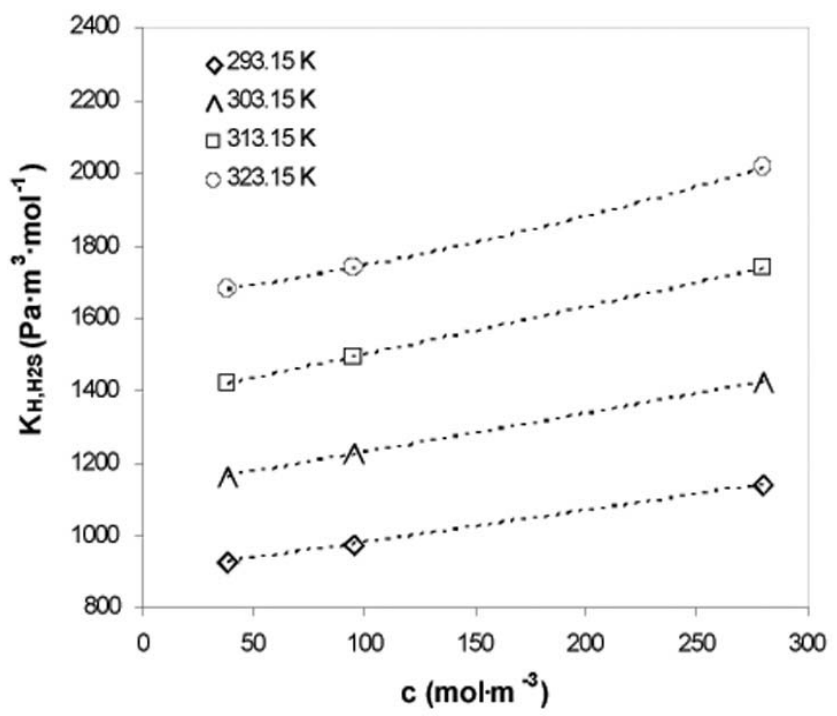

Fig. (1). Influence of temperature and chelate concentration on Henry's law constant of hydrogen sulfide in CDTA-Fe(II) solutions $(\mathrm{pH}=2.2)$ [16].

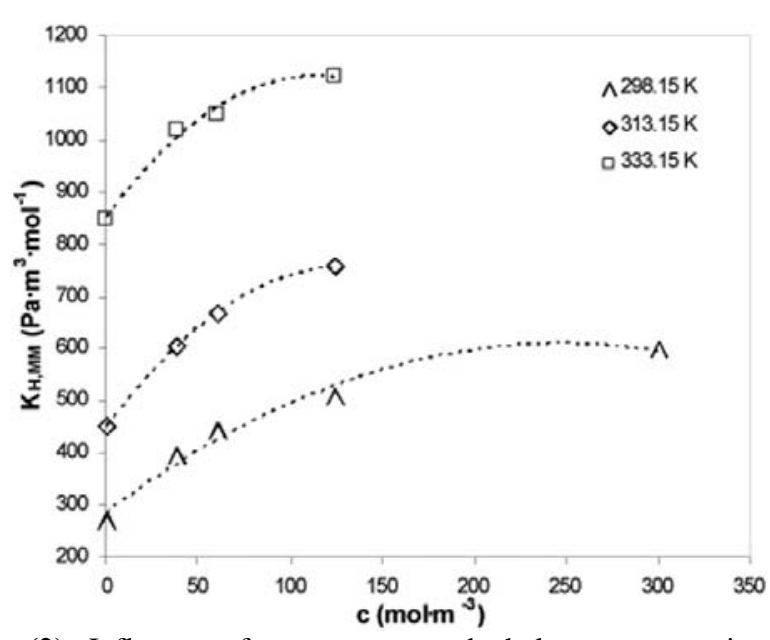

Fig. (2). Influence of temperature and chelate concentration on Henry's law constant of methyl mercaptan in CDTA-Fe(II) solutions [17].

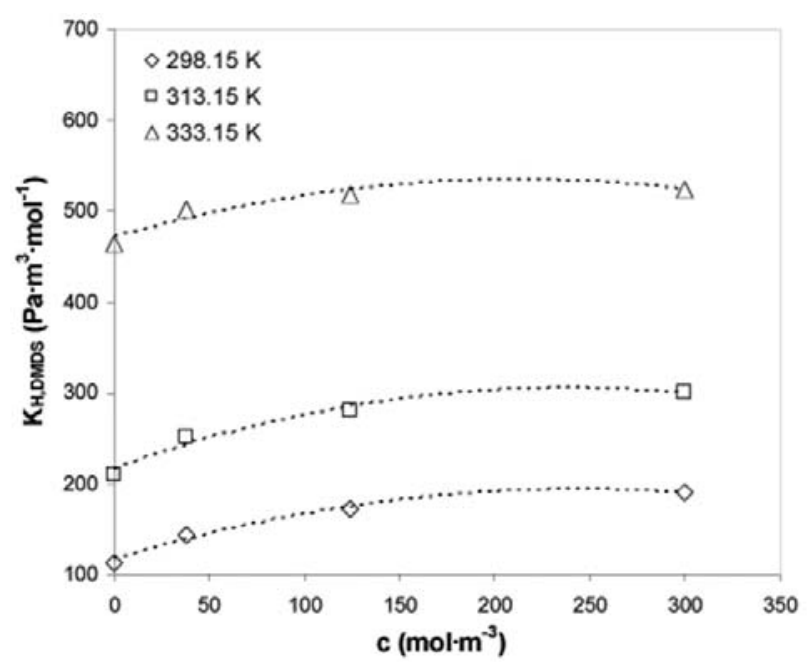

Fig. (3). Influence of temperature and chelate concentration on Henry's law constant of dimethyl disulfide in CDTA-Fe(III) solutions $(\mathrm{pH}=3.5)$ [19].

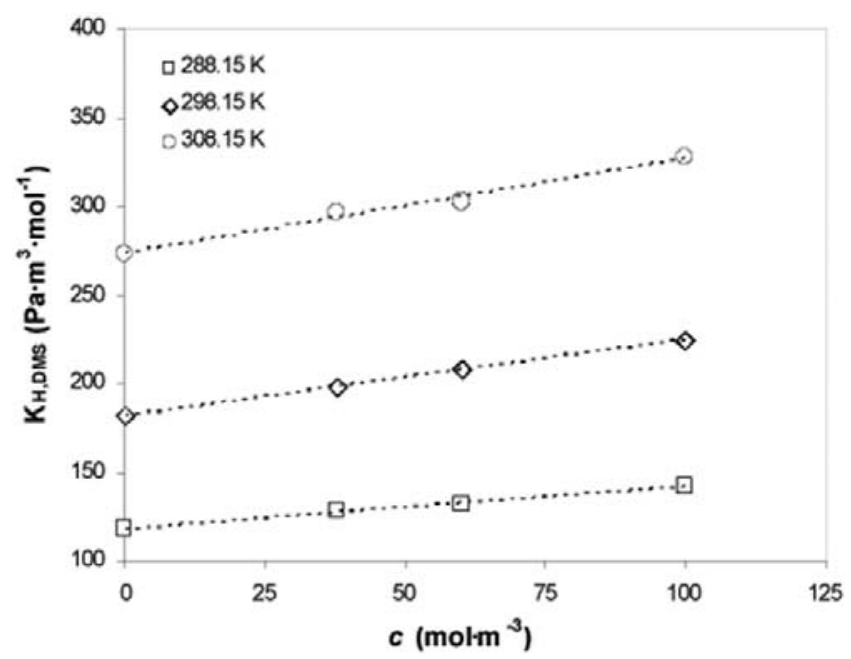

Fig. (4). Influence of temperature and chelate concentration on Henry's law constant of dimethyl sulfide in CDTA-Fe(III) solutions $(\mathrm{pH}=2.6)$ [18]. 
The most important influence is observed in the case of MM, and the less important in the case of DMS (Fig. 5).

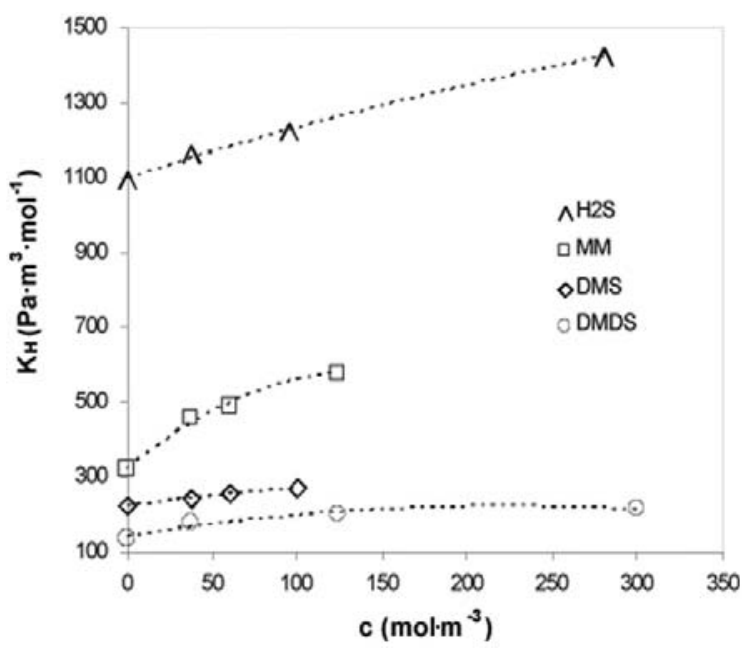

Fig. (5). Influence of chelate concentration on Henry's law constants at $303.15 \mathrm{~K}$ (acidic pH conditions (2.2-3.5)) [16-19].

An increase of CDTA concentration over $100 \mathrm{~mol} \cdot \mathrm{m}^{-3}$ leads to a much more significant decrease of $\mathrm{H}_{2} \mathrm{~S}$ solubility, than in the case of DMDS. However, temperature has an important influence on the solubility in the studied solutions (Figs. 1-4 and 6). Considering for all sulfur components a dependence of the Henry's law constant on the inverse temperature expressed as

$\ln \left(K_{H}\right)=A+B / T$

where the constant B is a function of the enthalpy of solution, it can be observed that the temperature influence varies in the order: DMS $>$ DMDS $>\mathrm{MM}>\mathrm{H}_{2} \mathrm{~S}$. Moreover, the solution enthalpy values for DMS and DMDS are very close. The exothermic solution enthalpy values of all these compounds are consistent with the negative temperature coefficients of solubility in the studied solutions. Concerning the solution $\mathrm{pH}$, it was generally varied between 2.2 and 8.5. For all sulfur compounds, only a very slight influence of $\mathrm{pH}$ on the solubility was observed. In all graphical representations (Figs. 1-6), only acidic conditions were therefore considered for highlighting the concentration and temperature influence on these sulfur compounds solubility.

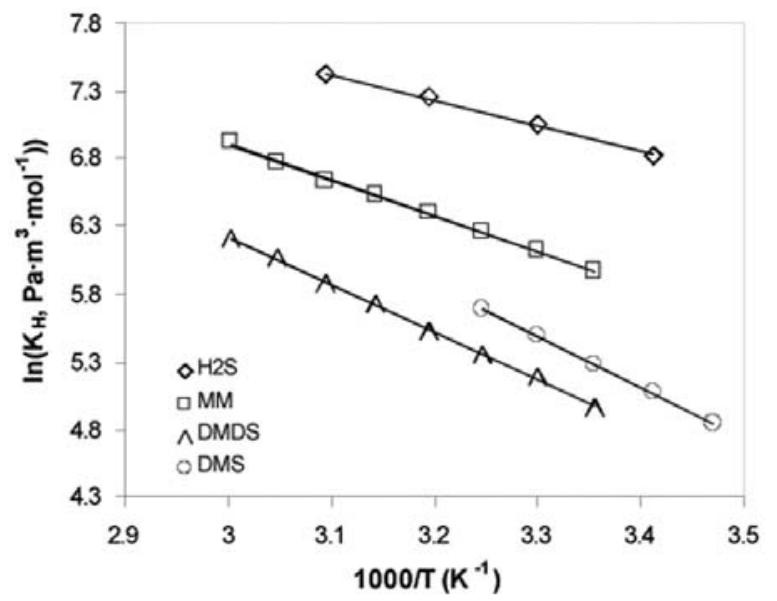

Fig. (6). Logarithms of Henry's law constants as a function of the inverse temperature (acidic $\mathrm{pH}$ conditions (2.2-3.5)) [16-19].

\section{CONCLUSIONS}

The total reduced sulfurs including hydrogen sulfide, methyl mercaptan (methanethiol), dimethyl sulfide and dimethyl disulfide can occur naturally in the environment and can also be present in numerous industrial gaseous streams (petroleum, natural gas, some chemical industries like the pulp and paper industry). Because the TRS compounds are formed in the Kraft pulping process and present a toxic and corrosive character, they must be removed down to very low concentration levels. The physical solubility of these four compounds in aqueous iron/CDTA alkaline solutions is an essential parameter for designing the complete scrubbingabsorption process based on the concept of alkaline oxidative scrubbing of TRS for eliminating the odor and converting them into valuable sulfur. Solubility data on systems containing hydrogen sulfide, methyl mercaptan, dimethyl sulfide, and dimethyl disulfide in Fe-Chelate aqueous solutions are available in a specified range of temperature, chelate concentration and $\mathrm{pH}$, in accordance to the typical operation conditions of iron chelate based procedure.

\section{REFERENCES}

[1] M. C. Iliuta and F. Larachi, "Solubility of total reduced sulfurs (hydrogen sulfide, methyl mercaptan, dimethyl sulfide and dimethyl disulfide) in liquids", J. Chem. Eng. Data, vol. 52, pp. 2-19, January 2007.

[2] G. Busca and C. J. Pistarino, "Technologies for the abatement of sulphide compounds from gaseous stream: a comparative overview", Loss Prev. Proc. Ind., Vol. 16, pp. 363-371, September 2003.

[3] A. Normandin, L. Belley, M. Aucoin and C. Gagnon, "Chemical oxidation of TRS in NCG using chlorine dioxide: reaction", Pulp\&Paper, October 2005 (http://www.paperloop.com/db_area/ archive/p_p_mag/2005/0010/02.html)

[4] K. V. Sarkanen, B. F. Hrutfiord, L. N. Johanson and H. S. Gardner, "Kraft Odor", TAPPI, vol. 53, pp. 766-783, May 1970.

[5] M. Järvensivu, R. Lammi and J. Kivivasara, "Odor abatement system of the modern pulp mill and relative importance of the prevailing TRS emission sources", in TAPPI Proceedings of the Environmental Conference \& Exhibition, 1997, pp. 645-665.

[6] R. P. Green and G. Hough, "Chemical recovery in the alkaline pulping process", $3^{\text {rd }}$ ed., TAPPI Press, Atlanta, GA, USA, 1992.

[7] M. Järvensivu, J. Kivivasara, J. and K. Saari, "Evaluation of various alternatives to reduce TRS emission of the lime kiln", in TAPPI Proceedings of the International Chemical Recovery Conference, 1998, pp. 519-535.

[8] B. O'Connor, D. Phaneuf and T. Dunn, "Reduction of total reduced sulphur (TRS) from Kraft mill emission vents using residual bleach plant chlorine dioxide", in TAPPI Proceedings of the International Environmental Conference, 1999, pp. 891-898.

[9] E. Traufer and M. Caglar, "Regenerative method for removing sulfides from gas stream”, U. S. Patent 5,698,171, December 16, 1997.

[10] G. A. Luna, "Process for scavenging hydrogen sulfide and mercaptan contaminants from a fluid", U. S. Patent 6,063,346, May 16, 2000.

[11] K. S. Cho, M. Hirai and M. Shoda, "Enhanced removability of odorous sulfur-containing gases by mixed cultures of purified bacteria from peat biofilters", J. Ferment. Bioeng., vol. 73, pp. 219224, March 1992.

[12] S. Asai, H. Nakamura and H. Aikawa, "Absorption of hydrogen sulfide into aqueous ferric chloride solutions", J. Chem. Eng. Jpn., vol. 30, pp. 500-506, March 1997.

[13] T. Tekin, N. Boyabat and M. Bayramoglu, "Kinetics and mechanism of aqueous oxidation of $\mathrm{H}_{2} \mathrm{~S}$ by $\mathrm{Fe}^{3+,}$, Int. J. Chem. Kinet., vol. 31, 331-335, May 1999.

[14] H. J. Wubs and A. C. M. Beenackers, "Kinetics of $\mathrm{H}_{2} \mathrm{~S}$ absorption of EDTA and HEDTA", AIChE J., vol. 40, pp. 433-444, March 1994.

[15] M. C. Iliuta and F. Larachi, "solubility of oxygen in aqueous solutions of $\mathrm{Fe}(\mathrm{III})$ complexes of trans-1,2-cyclohexanediami- 
netetracetic acid (CDTA) as a function of temperature and chelate concentration", J. Chem. Eng. Data, vol. 49, pp. 1691-1696, November 2004

[16] M. C. Iliuta, F. Larachi and B. P. A. Grandjean, "Solubility of hydrogen sulfide in aqueous solutions of Fe(II) complexes of trans1,2-cyclohexanediaminetetraacetic acid", Fluid Phase Equilib., vol. 218, pp. 305-313, April 2004.

[17] M. C. Iliuta and F. Larachi, "Gas-liquid partition coefficients and henry's law constants of methyl mercaptan in aqueous solutions of Fe(II) chelate complexes", Fluid Phase Equilib., Vol. 253, pp. 124129, May 2007.
[18] M. C. Iliuta and F. Larachi, "Gas-liquid partition coefficients and henry's law constants of DMS in aqueous solutions of $\mathrm{Fe}(\mathrm{II})$ chelate complexes using the static headspace method", J. Chem. Eng. Data, vol. 50, pp. 1700-1705, September 2005.

[19] M. C. Iliuta and F. Larachi, "Solubility of dimethyldisulfide (DMDS) in aqueous solutions of $\mathrm{Fe}(\mathrm{III})$ complexes of trans-1,2cyclohexanediaminetetraacetic acid (CDTA) using the static headspace method", Fluid Phase Equilib., vol. 233, pp. 184-189, June 2005.

[20] I. Iliuta and F. Larachi, "Concept of bifunctional Redox ironchelate process for $\mathrm{H}_{2} \mathrm{~S}$ removal in pulp \& paper atmospheric emissions", Chem. Eng. Sci., vol. 58, pp. 5305-5314, December 2003. 